\title{
O nativismo crítico e germanista de Sílvio Romero
}

\author{
Marcelo Chiaretto \\ Universidade Federal de Minas Gerais
}

Resumo: $O$ artigo busca estudar certas noçôes críticas de Silvio Romero e identificar a posteriori a conformação de um pensamento germanista apto a defender uma concep̧̧ão bem particular de nativismo crítico na literatura brasileira.

Palavras-chave: Sílvio Romero, Nativismo, Romantismo brasileiro e alemão.

É relevante recordar continuamente que a crítica literária se manifestou no Brasil com o Romantismo. Diante de tal constatação, faz-se do mesmo modo continuamente necessário examinar qual era o ângulo de visão e a opinião (ou opiniões) que melhor fundaram e orientaram um pensamento crítico que, na época, haveria de ser francamente coletivista e agregador, ao mesmo tempo que digno da atenção das nações reconhecidas como civilizadas. Sob esse ponto de vista, alguém que assumisse a função de um crítico romântico brasileiro seria obrigado a entender que seu papel não estaria relacionado somente com o estabelecimento de um cânon e a eleição de seu melhor método de avaliação. Simultaneamente, seu trabalho seria também o de criar uma ideia de literatura brasileira, para que assim esta pudesse agir coletivamente e ser reconhecida.

Levando-se em conta a realidade histórica do Brasil recémindependente, Antonio Candido aponta: 
Impõe-se o estudo da crítica no período em apreço, porque ela é de certo modo a consciência da literatura, o registro ou reflexo das suas diretrizes e pontos de apoio. [...] Devemos, pois, entender por crítica, no período estudado, em primeiro lugar as definições e interpretações gerais da literatura brasileira; em seguida, os esforços para criar uma história literária, superando a crítica estática e convencional do passado. ${ }^{1}$

Nota-se que a noção de crítica romântica brasileira se apresenta intimamente conectada a uma teoria nativista literária. Essa teoria teve no Brasil, como se sabe, um iniciador não brasileiro, ou melhor, franco-brasileiro, Ferdinand Denis. Junto a ele - e junto de suas concepções -, tem-se Almeida Garrett e o grupo da Revista Niterói (1836), dentre os quais Gonçalves de Magalhães, Porto Alegre e Pereira da Silva. Novos seguidores da mesma teoria se introduzem para fundar a Minerva Brasiliense (1843), podendo-se citar o chileno Santiago Nunes Ribeiro, Joaquim Norberto e o francês Emílio Adet. Na Guanabara (1849), a terceira e última transmutação, surge ainda Fernandes Pinheiro.

Entre os tantos papéis de considerável importância realizados pela crítica, um há de ser elucidado com especial atenção. Como foi apontado, a crítica brasileira representava uma espécie de magna orientação ou urgente reorientação, tendo em vista os tempos anteriores ao Romantismo, vistos então como sumamente não-brasileiros ou antipatrióticos. Dessa maneira, o enfoque seria direcionado em atenção ao que fosse convencionado brasileiro, o que liga esta noção diretamente ao romântico. Em oposição a este, afirmar-se-ia o clássico, a "poesia dos antigos", o erudito português "não-popular", ou seja, a poesia daqueles que viviam passivamente em meio à submissão colonial, algo muito distante de uma "autêntica" literatura nacional e romântica. Assim, seguir o pensamento clássico indiciaria repetição, uma rotina que impediria a manifestação do potencial criador presente em todo poeta de fato inventivo. Contudo, vê-se que tal inventividade não teria propriamente relação com experimentações poéticas, mas sim com um "universo fictício além da vida", em outras palavras, com um processo de transformação da realidade tendo em vista a ocultação dos pontos desfavoráveis e desmedida ênfase ao favorável. Nesse enfoque, a visão documentalista prevaleceria e dominaria com o endosso indefectível da crítica romântica brasileira.

1. CANDIDO. Formação da literatura brasileira, p. 285. 
É nesse momento que se pode verificar a importância básica de românticos europeus para o primeiro movimento crítico brasileiro. A moderna crítica literária fomentada pelos alemães Herder e A. Schlegel e pela francesa Madame de Staël no século XVIII apresentava argumentos anticlassicizantes aptos a possibilitar a expressão de povos nascentes, como seria o caso brasileiro. Em outras palavras, essa crítica inovadora fundamentou e propagou a cisão definitiva entre o clássico e o romântico, possibilitando às nações emergentes uma coerente relação: o clássico, a poética refratária a mudanças, distante do popular ecletismo, se ligaria à metrópole; o romântico por sua vez poderia então atender às nações recém-independentes desprovidas de tradição e história (conforme uma visão ocidental, é bom dizer).

Segundo Antonio Candido, as críticas românticas de A. Schlegel e de Staël, assim como a teoria do "nativismo romântico" de Chateaubriand e de Bernardin de Saint-Pierre, foram introduzidas, propagadas e vulgarizadas no Brasil pelo francobrasileiro Ferdinand Denis. ${ }^{2}$ Este teria então como fiéis seguidores talvez os mais importantes críticos do primeiro Romantismo como, por exemplo, Gonçalves de Magalhães, Pereira da Silva, Joaquim Norberto e Santiago Nunes Ribeiro. Como bem relacionou Antonio Candido, Norberto se aplicaria em desenvolver as ideias de Magalhães, ou melhor, a maneira por que este expunha as ideias de Denis. Pereira da Silva acompanharia Norberto, enquanto Santiago será um contraponto de fato muito estimulante. Tal crítica apenas seria superada por Sílvio Romero, já que "a nossa crítica romântica se desenrolou, até a História da literatura brasileira, como um repisar das premissas do Résumê,. ${ }^{3}$ De fato, esta seria a obra principal de Denis para o nacionalismo brasileiro, enquanto naquela - a História da literatura brasileira - Sílvio Romero substituiria Denis por Taine como guia para a caracterização dessa literatura.

\section{A espontaneidade de Sílvio Romero}

Com efeito, pode-se dizer que pelo menos um crítico brasileiro do século XIX logrou discutir a cultura e a história da literatura brasileira com um ponto de vista que controvertia e se contrapunha ao que o francês Ferdinand

2. Cf. CANDIDO. Formação da literatura brasileira, p. 289.

3. CANDIDO. Formação da literatura brasileira, p. 294. 
Denis defendia para a crítica romântica. Era uma perspectiva nativista declaradamente germânica, de onde se percebe uma eloquente compreensão da teoria relacionada ao Volksgeist-a concepção mística de "espírito nacional", de "espírito do povo", de "imaginário popular" que deveria governar o poeta conforme o pensamento do alemão Herder.

Pertencente à Escola do Recife, em que se nota também Tobias Barreto como outro germanista, Sílvio Romero produziu certos estudos que deixam explícita sua filiação a uma perspectiva nacionalista mística, populista, não tradicional e oposta a intervenções institucionais. Deve-se atentar, sobretudo, para o longo estudo História da literatura brasileira, de primeira edição datada em 1888 (inicialmente dois volumes para então se tornar os cinco da edição de 1943, a mais recente), no qual o autor expõe de maneira reiterada sua preocupação com o desenvolvimento de um espírito nacional brasileiro. Conforme uma objetividade bem peculiar, Sílvio reclama um "espírito" de fato, um imaginário nativista no modelo germânico, ou seja, menos outorgado - menos burocratizado ou menos submisso ao poder imperial tradicionalista e aos projetos nacionais de literatos distantes da realidade do país - e mais espontâneo, mais público, menos engessado e mais efervescente. De acordo com uma perspectiva extremamente engajada e republicana, Sílvio procura exaltar uma literatura que desempenhasse de fato um papel ativo na formação da consciência do país - mesmo que à custa de choques violentos e radicais. Para tanto, seria fundamental o repúdio a qualquer tom encomiástico, de reverência conveniente ao poder estabelecido, conforme um certo patriotismo romântico.

$\mathrm{Na}$ introdução à obra A literatura brasileira e a crítica moderna (de 1880), Sílvio Romero aponta a priori o risco em se elaborar um texto de crítica no Brasil, pois "os nossos ledores grandes e pequenos, como bons burgueses, estão tranquilíssimos com tudo quanto os cerca, e repelem soberbamente aquilo que os possa perturbar". ${ }^{4}$ Nesse ponto de vista, toda intenção crítica seria vista, pelo pequeno público leitor brasileiro, como um nocivo recurso desestabilizador, algo que poderia fazer desmoronar a sólida visão consensual de literatura - e, por contiguidade, de nação - construída a duras penas pelos primeiros românticos.

4. ROMERO. In: CANDIDO. Silvio Romero: teoria, crítica e história literária, p. 3. Daqui em diante, após a citação, será indicada entre parênteses a página em referência. 
Sílvio ataca da mesma maneira o zeloso argumento de que "este país é novo, e sua literatura nascente". Para ele, a crítica seria interessante para animar debates e fortalecer a produção literária comprometida com o país. Sílvio indica então o que seria para ele o "exemplo da Alemanha":

Em que pode prejudicar ao desenvolvimento espiritual de um povo o estudo que mostre-lhe quais as suas conquistas históricas e suas aptidões imanentes? Longe de ser-lhe nocivo, é-lhe de todo animador; e, para mostrá-lo, basta lembrar o exemplo da Alemanha, cuja literatura tomou o soberbo ascendente, que a distingue, fundada na crítica, depois do grande movimento provocado por Lessing. (p. 3)

Assim, conforme o radicalismo de suas palavras, "para um povo que não tem vida própria, um dos mais deteriorados do Globo, espécie de contrabandistas do pensamento, só a crítica pode preparar um futuro melhor", já que consegue "desobstruir o terreno, juncado de velhos preconceitos e falsidades, assim como desfazer as legendas".

Buscando historicizar a cultura brasileira em vista de uma expressão popular de fato autêntica, o que estaria bem de acordo com a receita nativista herderiana pregada pelo pré-romantismo alemão, Sílvio observa que:

à força de desprezarmos a corrente de nossa própria história e pormonos fora do curso das idéias livres, eis-nos chegados ao ponto de não passarmos de ínfimos glosadores das vulgaridades lusas e francesas; eis-nos dando o espetáculo de um povo que não pensa e produz por si. (p. 4)

Mantendo o tom e colocando então o indianismo como alvo de suas discordâncias, o crítico brasileiro afirma:

Nas grandes nações da Europa, como a Inglaterra e a Alemanha, o romantismo foi, em parte, uma volta aos sentimentos populares, uma ressurreição do passado no que ele tinha de mais aproveitável. Não assim entre nós. O nosso velho lirismo [...] foi esquecido. A velha modinha foi abandonada. [...] Desprezada a vida histórica, atiramo-nos aos desvarios do ultra-romantismo posterior à revolução de Julho, com todos os seus enganos e meticulosas fascinações. A crítica não nos ensinou a produzir; os elementos da nossa história e do nosso pensamento não foram elucidados. O papel dos três concorrentes da nossa população não foi 
indicado, e um falso sentimento de nacionalidade jogou-nos para o caboclo, e glorificamo-lo. (p. 5)

Vê-se que nesse trecho o crítico lamenta o abandono da história brasileira ou a sua reafirmação dentro de um ambiente colonial (e colonizado) de permanente dependência, seja da metrópole, seja dos outros modelos europeus. Sílvio, com suas preocupações ligadas à necessidade da expressão popular, percebe que por trás do abandono da modinha e do velho lirismo haveria um pensamento elitista classicizante, próprio para ocultar qualquer caráter menos enobrecedor da ex-colônia que pudesse afetar o fascínio do estrangeiro. Para o agrado deste, "os elementos da nossa história e do nosso pensamento não foram elucidados", dada a conveniência em se glorificar o "caboclo", um fictício índio bom selvagem, conforme o indianismo vincado em teorias naturalistas europeias.

Evidenciando os frutos do Romantismo europeu que, entre outros, contribuiu para a fecunda renovação da poesia popular, Sílvio menciona que, diversamente, o Romantismo no Brasil "teve o prestígio de falsificar e obscurecer o estudo de nossas origens, e acumular trevas sobre os três primeiros séculos de nossa existência" (p. 5). Para se recuperar essa história, seria necessário então "convicções sinceras" e "caracteres intransigentes", algo que poderia, segundo Sílvio, incomodar os "poderosos do dia" (p. 6).

Sob o prisma proporcionado agora pela obra (ou pelo conjunto) História da literatura brasileira, Sílvio inicialmente determina os quatro movimentos mais relevantes da literatura do Brasil (a escola baiana, a mineira, a fluminense e a "nacional" dos fins do século XIX), para então asseverar sobre a escola fluminense, fundadora do Romantismo:

A fluminense da primeira metade do XIX século, (foi) desenvolvida principalmente na corte do império, sob a inspeção do governo, ora com fluminenses, como Gonçalves de Magalhães e Macedo, ora com provincianos, que eram atraídos ao Instituto Histórico para serem ali desnorteados e separados do país, como Gonçalves Dias e Porto-Alegre.

Percebe-se que o crítico é bem objetivo sobre os entraves gerados bem como sofridos - pelos primeiros românticos brasileiros. É uma produção literária

5. ROMERO. História da literatura brasileira. In: CANDIDO (Org.). Sílvio Romero: teoria, crítica e história literária, p. 12. 
quase "imperial", inspecionada pelo governo e realizada por intelectuais intimamente relacionados com este mesmo governo, uma vez que se veem na condução de órgãos governamentais necessitados de legitimação pública nacional. Entretanto, na condução desses órgãos, tais intelectuais, de forma contraditória, acabavam por se distanciar da realidade do país, já que trabalhavam com os olhos atentos a uma realidade histórica marcadamente ideal ou projecional.

Examinando a representatividade da primeira literatura romântica e o grave problema do público leitor em um país de mínima alfabetização, assim como meditando sobre os "autores", Ś́lvio declara:

Quem entre nós escreve e quem entre nós lê? Não são, de certo, os lavradores, os negociantes, os criadores, os industriais, os políticos, nem os administradores. Somente as classes acadêmicas e alguns empregados públicos saídos dessas classes. É a regra geral. (p. 13)

O crítico mostra-se insatisfeito com o permanente ambiente colonizado, mesmo após mais de sessenta anos de independência. Essa "neocolonização" descaracterizaria o país, uma vez que ainda persistiria o costume de reproduzir indiscriminadamente a cultura estrangeira, no caso a francesa, quando não a da ex-metrópole. Tal constatação indiciaria a indiferença por todo produto intelectual que se apresentava como "nacional":

O império continuou, sob um falso constitucionalismo, o velho absolutismo e a antiga miopia da metrópole. Que os norte-americanos continuem a trilhar as sendas da inteligência inglesa, é coisa que deve ser aplaudida; porque a Inglaterra sabe pensar; que o Brasil continue a copiar Portugal, é uma triste herança da história, que todo bom patriota deve modificar e corrigir. (p. 13)

A organização colonial que ainda se mantinha no Império seria responsável por um processo de inutilização da cultura brasileira, uma vez que "descalabros" continuavam a ser cometidos contra a população no roldão de um triste passado: a instrução permanecia quase nula, firmando assim um "povo" sem iniciativa e sem autonomia devido à educação jesuíta, com desenvolvimento da memória, prejuízo do raciocínio e uniformização de culturas: "Daí saiu o império do Brasil, país de senhores, de grandes, de magnatas; mas terra sem povo, no alto sentido da palavra!" (p. 14) 
O crítico ataca também o que se pode denominar de "obsessão pelo equilíbrio", a cultura do consenso e da cordialidade desenvolvida oportunamente no Brasil, apta a transformar qualquer querela em pacto para dinamizar privilégios:

A nossa Independência, sendo um fato histórico de alcance quase nulo, não tendo havido aqui uma revolução que afogasse os velhos preconceitos, não nos abriu uma fase de autonomia e liberalismo. A república nada tem melhorado neste sentido por enquanto. [...] A revolução é um dos processos indispensáveis à marcha das nações. Se nós a tivéssemos feito, não estaríamos hoje quase nas mesmas condições do regime colonial, anterior a 1822. A grande pobreza das classes populares, a falta de instrução e todos os abusos de uma organização civil e social defeituosa, devem ser contados entre os empecilhos ao desenvolvimento de nossa literatura. (p. 14-15)

Para dar vida ao Volksgeist brasileiro, o autor receita aos intelectuais um contato direto e autêntico com a população, para a qual buscariam dizer a "verdade" histórica, a realidade concreta, e não as "inovações insensatas". A meta seria o estabelecimento de uma nação culta, livre e original, transformando em povo o "rebanho mole e automático" que compunha as classes menos favorecidas: "a situação funcional da população brasileira pode ser expressa em uma só palavra: o Brasil não tem povo!" (p. 15)

Frisando os conceitos de Zeitgeist - o espírito da época - e de Allgeist-o espírito comum -, "que determina a corrente geral das opiniões de um povo" (p. 18), Sílvio Romero reafirma a falta de um estudo particular e apurado de todas as ramificações da atividade popular, nos sentidos artístico, literário e religioso. O problema estaria na literatura "incolor" aqui produzida, baseada em escolas francesas (hugoanismo, baudelairianismo e zolaísmo) sem qualquer inventividade de fato, já que "se imitam mudando apenas as tendências". Ele então relembra uma sua recomendação:

Tanto quanto se deve aos povos fracos aconselhar que busquem exemplo nas grandes nações criadoras, eu avisara os brasileiros das vantagens que lhes podem advir da lição das gentes anglo-germânicas, corrigindo as debilidades latinas. [...] Fechado o ciclo da antigüidade, decaído o império romano, às raças germânicas coube a herança e a tarefa de preparar a Idade Média, criar as nações novas e abrir a era moderna. (p. 19) 
Nessa direção, Sílvio faz uma longa relação das contribuições germânicas para as letras e ciências, algo que poderia ser bem aproveitado para nações ainda alienadas desses frutos de outras civilizações. Coerente com um pensamento germânico ligado às raízes, ao torrão natal, o autor aponta novamente o caminho para a afirmação do Volksgeist no Brasil:

Há um espírito geral que os compreende (os tipos que compõem a pátria), que os domina; é o espírito popular, subjetivo à nação, que não se pode fabricar, que deve ser espontâneo. O caráter nacional não está em se falar em maracás e tangapemas, tampouco está em se lembrar o xiba, o bumba-meu-boi, o samba, etc. Deve estar no sentimento original, no sentir especial do brasileiro. O nacionalismo não há-de, pois, ser uma tese objetiva de literatura, a caçada de um título; deve-se antes estudar o nosso povo atual em suas origens, em suas produções anônimas, definindo a sua intimidade emocional, a sua visualidade artística. (p. 21)

Nota-se que este texto, revisto pelo autor e republicado em 1902, se aproxima bastante do que mencionou Machado de Assis no memorável ensaio "Instinto de nacionalidade", de 1873. Neste texto, pode-se ler:

Um poeta não é nacional só porque insere nos seus versos muitos nomes de flores ou aves do país, o que pode dar uma nacionalidade de vocabulário e nada mais. Aprecia-se a cor local, mas é preciso que a imaginação lhe dê os seus toques, e que estes sejam naturais, não de acarreto.

Verifica-se nos dois críticos uma concepção de nacionalidade e de nativismo que estariam forjadas não sobre atitudes calculadas conforme disposições do poder estabelecido. Opostamente, era necessário se estudar a noção de pertencimento, algo não controlável ou concreto, porém místico, particular, instável, natural e sempre coletivista. Segundo um processo de reflexão em harmonia com a teoria herderiana do Sturm und Drang alemão que cita a "unidade na multiplicidade" literalmente, Sílvio Romero acrescenta:

Não sonhemos um Brasil uniforme, monótono, pesado, indistinto, nulificado, entregue à ditadura de um centro regulador das idéias. [...] A

6. MACHADO DE ASSIS, J. M. Obras completas, p. 807. 
grande alma nacional, apesar de muito batida de infortúnios, não caiu ainda na imobilidade chinesa. [...] Que seria melhor: uma pátria uniforme, morta, gelada, ou vivace e múltipla em suas manifestações? Daí não vem perigo. Não se chama isto dividir a literatura nacional em duas; é apenas afirmar a unidade na multiplicidade. (p. 24)

As relações com a teoria nacionalista de Herder e sua indicação para resolver a situação nacional brasileira de fato se espalham pelos livros do crítico em questão. Este, a propósito, chega a citar textualmente o pensador alemão em certos momentos. Há a menção de Herder como um dos "grandes guias do pensamento germânico" e um dos responsáveis pela "agitação literária e científica que se resolve no romantismo alemão", uma tendência cuja influência maior, segundo Romero, apareceria no Caramuru e no Uraguai. ${ }^{7}$ Em outro livro, Estudos de literatura contemporânea, de 1885, Herder é citado, junto a Lessing, como um dos pais da crítica moderna, que teria assim sua origem na Alemanha. ${ }^{8}$ Herder, agora acompanhado de Thierry e Renan, é também relacionado dentre os mestres da Etnologia, um dos que teriam corroborado a introdução do princípio etnográfico nos estudos do próprio Sílvio. ${ }^{10}$ Nos Novos estudos de literatura contemporânea, Herder é novamente incluído em um grupo notável, sendo agora parte do pequeno grupo dos "grandes transformadores das ciências do homem".

Com o suporte nessa teoria, Sílvio busca fugir do nacionalismo do pitoresco (que corresponde à ânsia europeia pelo exótico) para elaborar um tema capaz de fundar a diferença realmente concreta do Brasil diante das outras civilizações. Seria assim um tema a ser exaltado radicalmente pela produção literária brasileira, que parecia ainda se perder no respeito à deslocada ótica europeia nativista determinada pelos franceses, como Ferdinand Denis.

7. ROMERO. História da literatura brasileira. In: CANDIDO (Org.). Sílvio Romero: teoria, crítica e história literária, p. 34.

8. ROMERO. História da literatura brasileira. In: CANDIDO (Org.). Sílvio Romero: teoria, crítica e história literária, p. 87.

9. ROMERO. História da literatura brasileira. In: CANDIDO (Org.). Sílvio Romero: teoria, crítica e história literária, p. 88.

10. ROMERO. História da literatura brasileira. In: CANDIDO (Org.). Sílvio Romero: teoria, crítica e história literária, p. 119.

11. ROMERO. História da literatura brasileira. In: CANDIDO (Org.). Sílvio Romero: teoria, crítica e história literária, p. 130. 
O crítico também enfatiza a contraposição à centralização do pensamento nacional e a oposição à imitação do parisismo como convenientes ideias anglo-germânicas. Com essas noções em mente, ele faz um alerta ao Brasil com a finalidade de combater o equívoco impulso padronizador que não respeitava as variações étnico-históricas: "O Brasil éo Rio de Janeiro!... dizemos, macaqueando inconsideradamente a frase - a França é Paris!...” (p. 22, os itálicos são do autor).

\section{Um nativismo crítico}

Para fugir da dependência cultural marcadamente francesa, Sílvio demonstra o engano em se celebrar o índio como símbolo nacional do nativismo brasileiro, em detrimento daquele que seria, de fato, a afirmação da diferença cultural, a afirmação do Volksgeist brasileiro: o mestiço. No livro III da História da literatura brasileira, o autor argumenta que não há como se determinar a existência do índio, do negro ou do branco português se considerarmos pelo menos três séculos de história e de intensa mistura de raças. Segundo suas palavras, houve uma "desaparição progressiva" ou, como ele corrige em seguida, uma "transformação das duas raças inferiores e a sua integração em um produto novo pela mestiçagem”, incluindo-se aí ainda o português que "não ficou incólume à ação modificadora do meio, ele também se transformou". Assim, "o espetáculo de nossa história é um espetáculo de transformação de forças étnicas e de aptidões de três culturas diversas, de três almas que se fundem".

Com efeito, se o autor enfatiza reiteradamente que a literatura brasileira, como todas as literaturas do mundo, deve ser a expressão positiva do estado emocional e intelectual, das ideias e dos sentimentos de um povo - sempre na receita nativista popularizante dos românticos alemães -, este "povo" por seu lado tem uma caracterização:

Ora, nosso povo não é o índio, não é o negro, não é o português; é antes a soma de todas estas parcelas atiradas ao cadinho do Novo Mundo. São as gerações crioulas, que, deixadas de parte as nostalgias dos progenitores, esqueceram-se delas para amar este país e trabalhar na

12. ROMERO. História da literatura brasileira. In: CANDIDO (Org.). Silvio Romero: teoria, crítica e história literária, p. 28. Daqui em diante, após a citação, será indicada entre parênteses a página em referência. 
formação de uma pátria nova. [...] Uma literatura tem uma base, tem elementos e tem órgãos. A base da nossa é o sentimento do brasileiro, como nação à parte, como produto étnico determinado; os elementos são as tradições das três raças sem predomínio de uma sobre as outras; os órgãos são os nossos mais notáveis talentos, todos aqueles que sentiram como brasileiros. (p. 54-55)

Nesse ponto de vista, o índio não seria de fato brasileiro, uma vez que teria vivido em uma terra sem qualquer correspondência com o sentimento nativista do que é ser Brasil, ser pátria, ou melhor: ser Estado segundo o ponto de vista moderno. Conforme Sílvio Romero, faltaria assim à figura do silvícola uma representatividade mítica para que então pudesse simbolizar o elemento primitivo, algo original e, dessa forma, autenticamente nacional.

Negando a presença do Volksgeist brasileiro no indianismo, o autor enfatiza ainda a falta de contribuições históricas da população indígena:

Embalde se procurará um sério e profundo princípio social e civil deixado por ele. Em pouco modificou o gênio, o caráter dos conquistadores. A razão está, me parece, nesta lei histórica da conquista da América: quanto mais civilizada era a população indígena, tanto mais resistia e deixava vestígios. [...] Um povo que fugiu dificilmente poderia deixar impressos no vulto do que lhe ocupou o lugar os seus toques, ainda os mais decisivos. O índio não é o brasileiro. O que este sente, o que busca, o que espera, o que crê, não é o que sentia, procurava, ou cria aquele. (p. 66)

Nota-se que o autor defende aqui uma contribuição histórica sob um ângulo caracteristicamente modernizante, uma vez que não compreende outra contribuição que não seja "um sério e profundo princípio social e civil". Em outras palavras, vê-se uma preponderância do urbano sobre o agrário, por ser este mais difuso e menos dimensionado em termos de "princípios sociais e civis".

Corroborando pré-julgamentos ao tempo que os contestando, Sílvio Romero informa que o predomínio do indianismo se deve a um preconceito difícil de ser combatido:

Causas numerosas e especiais contribuíram para arraigá-lo. [...] Na literatura (o indianismo) aparece como um protesto contra os invasores. [...] $\mathrm{Na}$ esfera social o índio tem mais simpatias, deixou há mais tempo de ser escravizado e, por ser menos escuro do que o negro, é mais querido. (p. 49) 
Daí o autor evidenciar a negligência sofrida pelo negro, uma raça "que oferece interessantíssimos problemas" e que, historicamente, representa um "papel mais eminente do que o botocudo, ente fraco, desequilibrado e prestes a extinguir-se" (p. 49). Segundo o severo darwinismo de Ś́lvio, o negro seria fundamental no processo de caracterização racial brasileira pelo caráter menos débil e por estar mais próximo do elemento mestiço, o único com efeito nacional: "o negro e seu parente mestiço tocam o nosso povo bem de perto. Não sejamos presunçosos, nem tenhamos medo de dizer a verdade".

Como autor a simbolizar o "genuíno brasileiro", Sîlvio indica Gonçalves Dias, um filho de português com mameluca, "um mestiço físico e moral que será ainda por muitos séculos uma das mais autênticas manifestações da alma deste povo" (p. 64). Este autor romântico estaria assim, de acordo com Sílvio, inserido no grupo dos que realizam um nacionalismo mais subjetivo, mais "do fundo d'alma", espontâneo, em vista do nacionalismo exterior, baseado na escolha de assuntos. Marcando bem o seu germanismo, Silvio chega a citar a obra Goetz von Berlichingen, enfatizando que nela Goethe teria sido menos "alemão" - ou seja, mais objetivo e menos espontâneo - do que em comparação com obras como o Fausto ou com Hermann e Dorothea (p. 29).

Percebe-se assim que Sílvio Romero defende uma concepção nativista de nação conforme os moldes prescritos em grande parte pelo alemão Herder. De fato, o crítico brasileiro leva em conta uma noção mítica em vista de uma expressão popular, não erudita, do que seria de fato único e original, incomensurável, digno de fazer com que a razão perca sua autonomia a fim de trabalhar por um projeto gerado pelo próprio Gênio do povo. Este Gênio, ligado à ideia de genuíno, traria à tona a ideia da diferença, algo muito caro ao pensamento nacionalista alemão por romper com o absolutismo do modelo clássico. É a noção de ecletismo, salientada por Herder e desenvolvida por A. Schlegel, sendo então amplamente explorada pelos românticos brasileiros, com o fim de destacar o contraste existente entre a metrópole portuguesa e a ex-colônia, assim como para fundar um lugar digno e autônomo para a nova nação no concerto das nações modernas.

Por outro lado verifica-se que, na visão de Sílvio, as expressões populares deveriam ser cultas e civilizadas de acordo com projetos modernizantes e evolucionistas, o que estabelece uma distinção com a concepção romântica alemã. Esta, crente na expressão do nacional-popular, mostrava-se desvinculada de qualquer projeto ou organização de corte evolucionista ou moderno, mas vinculada apenas a hábitos e tradições de sua única e indevassável cultura primitiva. 


\section{Ainda em busca da expressão popular}

Nesta relação com Herder (que obviamente não foi a única fonte de ideias), Sílvio indicia uma preocupação com uma educação popular, mas sobretudo republicana e moderna, que não fosse uma adaptação de casos exteriores desarraigados. Para o crítico brasileiro, o processo de modernização seria indispensável já que no Brasil "primitivo" (ou agrário) apenas eram favorecidas determinadas famílias de grandes latifundiários. Contrastando com uma Alemanha fundada em comunidades - algo realçado mesmo por Antonio Candido no prefácio a Raízes do Brasil ${ }^{13}$-, a cultura "primitiva" no Brasil era mantida em conformidade com um sistema patriarcal que encontrava suas forças em uma sociedade sem nenhuma ideia de igualdade ou democracia. Além disso, convém destacar que, no século XIX, o Brasil evidenciava uma organização social paradoxal e disparatada: havia noções de progresso, civilização e liberalismo convivendo ao lado de uma avassaladora lógica escravagista.

Atento a essa realidade, Sérgio Buarque chega a afirmar:

A democracia no Brasil foi sempre um lamentável mal-entendido. Uma aristocracia rural e semifeudal importou-a e tratou de acomodá-la, onde fosse possível, aos seus direitos ou privilégios, os mesmos privilégios que tinham sido, no Velho Mundo, o alvo da luta da burguesia contra os aristocratas. ${ }^{14}$

Em detrimento do sonho com vistas à instauração de uma sociedade moderna, imperavam no país famílias desinteressadas de política a disputar um prestígio tipicamente personalista em meio a uma anarquia sem perspectiva de controle. Como mencionou ainda Sérgio Buarque: "Em terra onde todos são barões não é possível acordo coletivo durável". ${ }^{15}$ Para romper essa ordem primitiva da ex-colônia, surge a perspectiva republicana, que se instala excluindo da mesma forma a população brasileira: "as práticas e usos do constitucionalismo parlamentar, posto que superiores às do presidencialismo atual, não assentaram jamais neste país em aspirações, impulsos, necessidades do povo". " Em outras palavras, eram

13. CANDIDO (prefácio). In: HOLANDA. Raizes do Brasil, p. XLVI.

14. HOLANDA. Raizes do Brasil, p. 119.

15. HOLANDA. Raizes do Brasil, p. 4.

16. ROMERO. História da literatura brasileira. In: CANDIDO (Org.). Sílvio Romero: teoria, crítica e história literária, p. 171. 
movimentos reformadores que se afirmavam de cima para baixo, de inspiração intelectual, sem a espontaneidade de uma expressão popular: "Nossa independência, as conquistas liberais que fizemos durante o decurso de nossa evolução política, vieram quase de surpresa; a grande massa do povo recebeu-as com displicência, ou hostilidade". ${ }^{17}$

Persiste assim o mito do povo cordial e pacífico. Em suma, daquele povo agradável ao estrangeiro, que deve repelir soluções violentas sob o risco de atrapalhar a fundação de uma nação, que a todos garantiria na qualidade de cidadãos e residentes de um paraíso tropical abençoado por Deus e invejado pelo Velho Mundo:

Desejamos ser o povo mais brando e o mais comportado do mundo. Pugnamos constantemente pelos princípios tidos universalmente como os mais moderados e os mais racionais. Fomos das primeiras nações que aboliram a pena de morte em sua legislação, depois de a termos abolido muito antes na prática. Modelamos a norma de nossa conduta entre os povos pela que seguem ou parecem seguir os países mais cultos, e então nos envaidecemos da ótima companhia. ${ }^{18}$

Tais constatações frisam bem as condições em que a sociedade brasileira da época se encontrava em termos de organização política. Nota-se uma estrutura que se empenha em solapar toda iniciativa que pudesse quebrar o pacto pelo consenso, que se empenha em projetar uma imagem e uma voz domésticas para um povo, negando assim toda espontaneidade nacional. Assim, para representar a nova nação sob o aspecto nativista, não haveria nessa perspectiva nem o índio, nem aqueles que um dia pudessem ser o povo.

17. HOLANDA. Raizes do Brasil, p. 119.

18. HOLANDA. Raizes do Brasil, p. 132. 


\title{
The critical and Germanist nativism of Silvio Romero
}

\author{
Abstract: This essay explores some of the critical concepts of Silvio Romero and \\ identifies a posteriori the conformation of a Germanist thought able to design \\ and defend a particular critical nativism in Brazilian literature.
} Keywords: Silvio Romero, Nativism, Brazilian and German Romanticism.

$$
\text { Referências }
$$

CANDIDO, Antonio. Literatura e sociedade. São Paulo: Cia. Editora Nacional, 1976.

CANDIDO, Antonio. Sílvio Romero: teoria, crítica e história literária. Rio de Janeiro: Livros Técnicos e Científicos; São Paulo: Edusp, 1978.

CANDIDO, Antonio. A educação pela noite e outros ensaios. São Paulo: Ática, 1989.

CANDIDO, Antonio. Formação da literatura brasileira. 2 v. 7. ed. Belo Horizonte: Itatiaia, 1993.

FREYRE, Gilberto. Casa-Grande e senzala. 30. ed. Rio de Janeiro: Record, 1992.

HERDER, J. G. Sämtliche werke. Berlin: Ed. B. Suphan, 1877-1913.

HERDER, J. G. Também uma filosofia da bistória para a formação da bumanidade. Trad. José M. Justo. Lisboa: Antígona, 1995.

HOLANDA, Sérgio B. Raizes do Brasil. 26. ed. Rio de Janeiro: José Olympio, 1994.

MACHADO DE ASSIS, J. M. Notícia da atual literatura brasileira. Instinto de nacionalidade. In: Obras completas. Rio de Janeiro: Livraria José Aguilar Ed., 1959.

RIBEIRO, S. N. Da nacionalidade da literatura brasileira. In: COUTINHO, A. (Org.). Caminhos do pensamento crítico. Rio de Janeiro: Pallas, 1980. v. I, p. 42-73.

ROMERO, Sílvio. História da literatura brasileira. Rio de Janeiro: José Olympio, 1943. $5 \mathrm{v}$.

SCHLEGEL, August W. Cours de Littérature Dramatique. Trad. Necker de Saussure, 2 v. Paris: Lacroix \& Cia, 1865.

SILVA, J. N. de Sousa. Bosquejo da história da poesia brasileira. Ed., apres. e notas José Américo Miranda. Belo Horizonte: Ed. UFMG, 1997.

STAËL, Madame de. De l'Allemagne. 2 v. Paris: G-Flammarion, 1968. 